\title{
Ecological Literacy Siswa SMA Adiwiyata dan Non Adiwiyata
}

\author{
Rahmadiani $^{1}$, Sugeng Utaya ${ }^{1}$, Syamsul Bachri ${ }^{1}$ \\ ${ }^{1}$ Pendidikan Geografi-Universitas Negeri Malang
}

\begin{tabular}{l}
\hline INFO ARTIKEL \\
\hline Riwayat Artikel: \\
Diterima: 08-03-2019 \\
Disetujui: 20-04-2019 \\
\hline
\end{tabular}

\section{Kata kunci:}

ecological literacy; high school student; ecological literacy; siswa SMA

\author{
Alamat Korespondensi: \\ Rahmadiani \\ Pendidikan Geografi \\ Universitas Negeri Malang \\ Jalan Semarang 5 malang \\ E-mail: rahmadiani.geo13@gmail.com
}

\begin{abstract}
ABSTRAK
Abstract: This study aims to compre the ecological literacy of students in adiwiyata and non adiwiyata schools. This study uses a quantitative approach. The sample in this study was grade XI students at SMAN 2 Malang, SMAN 4 Malang and SMAN 9 Malang. The sampling technique uses purposive sampling. Data analysis using one-way ANOVA test analiysis. This study obtained results: (1) there are differences in environmental knowledge in adiwiyata and non adiwiyata high schools, (2) there are differences in environmental care attitudes of students in adiwiyata and non adiwiyata high schools, and (3) there are no differences in students' skills in preventing environmental damage in adiwiyata and non adiwiyata high school
\end{abstract}

\begin{abstract}
Abstrak: Penelitian ini bertujuan untuk mengetahui perbandingan ecologoical literacy siswa pada sekolah adiwiyata dan non adiwiyata. Penelitian ini menggunakan pendekatan kuantitatif. Sampel pada penelitian ini siswa kelas XI di SMAN 2 Malang, SMAN 4 Malang dan SMAN 9 Malang. Teknik penentuan sampel menggunakan purposive sampling. Analisis data menggunakan analisis uji anova satu jalur (one way anova). Penelitian ini memperoleh hasil (1) terdapat perbedaan pengetahuan lingkungan pada SMA adiwiyata dan non adiwiyata, (2) terdapat perbedaan sikap peduli lingkungan siswa pada SMA adiwiyata dan non adiwiyata, dan (3) tidak terdapat perbedaan keterampilan siswa dalam mencegah kerusakan lingkungan pada SMA adiwiyata dan non adiwiyata.
\end{abstract}

Kerusakan atau pencemaran lingkungan sering terjadi di lingkungan sekitar siswa. Ketidaktahuan manusia mengenai masalah lingkungan dan rendahnya pengetahuan lingkungan menyebabkan terjadinya kerusakan lingkungan (Mahanal \& Utaya, 2014). Mengatasi dampak dari kerusakan lingkungan tersebut, diperlukan pengetahuan dan kesadaran tentang pentingnya lingkungan dan perubahan sikap serta perilaku peduli lingkungan pada diri seseorang yang disebut juga dengan ecological literacy. Menurut (Kemendikbud, 2013) menyatakan, sikap peduli lingkungan merupakan setiap individu memiliki tanggung jawab masing-masing terhadap sikap, dan secara umum faktor lingkungan yang memengaruhinya. Sikap dan perilaku lingkungan yang baik dipengaruhi oleh mereka yang memiliki pengetahuan lingkungan.

Ecological literacy (ecoliteracy) mengubah pemahaman dan memperkenalkan kepada masyarakat akan pentingnya kesadaran ekologis global. (Keraf, 2014) mengemukakan ecological literacy adalah pemahaman dimana keadaan seseorang telah memahami betapa pentingnya lingkungan hidup. Orang yang telah sampai pada tahan ecoliteracy adalah seseorang yang sangat memahami dan menyadari pentingnya menjaga, merawat serta melestarikan lingkungan yang merupakan tempat tinggal dan berkembangnya kehidupan. Manusia menata pola dan gaya hidup atas dasar yang digerakkan oleh kesadaran, sehingga pola dan gaya hidup manusia seimbang dengan lingkungan hidup.

(Rusmawan, 2017) menyatakan ecoliteracy dinilai dari tiga tahap kontinum, meliputi nominal, fungsional, dan operasional. Lebih lanjut, ketiga tahap tersebut diinterpretasikan oleh Moseley (2000), bahwa orang yang berada dalam tahap ecoliteracy nominal hanya memiliki sedikit pemahaman tentang isu lingkungan dan sedikit ketertarikan serta terbatasnya aksi terkait lingkungan. Selanjutnya dalam tahap functional mereka dapat menggunakan pengetahuan, pemahaman konsep, dan kemampuan berpikir untuk membangun rencana yang akan dilakukan berkaitan dengan isu lingkungan.

Membangun ecological literacy siswa yaitu melalui pendidikan. Salah satu cara untuk memiliki kesadaran akan pentingnya menjaga lingkungan melalui pendidikan dengan tujuan untuk membentuk manusia berkelanjutan yang memiliki kesadaran lingkungan.Menurut (Ardanita, Utaya, \& Ruja, 2017) pendidikan lingkungan berperan untuk mensosialisasikan dan mengajarkan perilaku yang bertanggung jawab terhadap lingkungan sekitar. Ecological literacy siswa dapat dilihat dengan 
pengetahuan lingkungan, sikap peduli lingkungan, keterampilan serta partispasi siswa dalam menjaga lingkungan. Hal tersebut diperkuat rumusan indikator oleh The Center for Ecoliteracy secara operasional komponen-komponen ecolitaracy menjadi seperangkat kompetensi utama untuk membantu anak muda hidup dalam masyarakat berkelanjutan.

Penelitian ini merujuk pada implementasi kompetensi ecoliteracy yang dikembangkan oleh The Centre for Ecoliteracy yang telah mengembangkan seperangkat "kompetensi inti" untuk membantu siswa dalam mengembangkan kemampuan sikap, pengetahuan danketerampilan ecoliteracy dalam upaya mendukung suistainable development. Kompetensi intitersebut mencakup aspek head (cognitive) competencies atau learning to know, heart(emotional) competencies atau learning to be, hands (active) competencies atau learning todo, dan spirit competencies atau learning to live together, (The Center For Ecoliteracy, 2014).

Salah satu program pemerintah yang dapat dijadikan sebagai alternatif dalam membangun ecological literacy siswa yaitu dengan mengimplementasikan program adiwiyata di sekolah. Program lingkungan yang dibentuk oleh pemerintah yaitu program adiwiyata guna mewujudkan masyarakat yang berkelanjutan yang telah dilaksanakan sejak tahun 2006 di sekolah dari tingkat sekolah dasar hingga sekolah menengah atas. Penelitian ini bertujuan untuk untuk mengetahui ecological literacy siswa pada sekolah adiwiyata dan non adiwiyata.

\section{METODE}

Penelitian Ecological literacy siswa SMA pada sekolah adiwiyata dan non adiwiyata menggunakan metode pendekatan penelitian kuantitatif. Populasi pada penelitian ini yaitu siswa kelas XI IPS. Berdasarkan tiga sekolah yang terpilih sebagai lokasi penelitian ini, yaitu SMAN 2 Malang, SMAN 4 Malang, dan SMAN 9 Malang. Penentuan sampel pada penelitian ini menggunakan teknik purposive sampling. Sampel dari penelitian ini yaitu masing-masing satu kelas siswa XI IPS dari sekolah adiwiyata dan non adiwiyata. Pengumpulan data menggunakan wawancara dan penyebaran angket. Instrumen yang digunakan dalam penelitian ini berupa daftar pertanyaan, tes essay untuk mengukur pengetahuan lingkungan siswa dan angketuntuk mengukur sikap peduli lingkungan dan keterampilan siswa dalam mencegah kerusakan lingkungan. Analisis data menggunakan uji Anova satu jalur (One Way Anova), analisis dilakukan menggunakan SPSS for windows 21.

\section{HASIL}

Data yang dianalisis dalam penelitian ini adalah data siswa dari aspek pengetahuan lingkungan, sikap peduli lingkungan, dan keterampilan dalam mencegah kerusakan lingkungan pada sekolah adiwiyata dan non adiwiyata. Hasil penelitian menunjukkan bahwa nilai rata-rata dari tiga aspek tersebut pada sekolah adiwiyata lebih tinggi dari sekolah non adiwiyata. Nilai rata-rata pengetahuan lingkungan pada sekolah adiwiyata mandiri yakni 75,15 pada sekolah adiwiyata nasional 72,10 dan 61,25 pada sekolah non adiwiyata. Hasil uji hipotesis pengetahuan lingkungan pada sekolah adiwiyata dan non adiwiyata dapat dilihat pada tabel 1 .

Tabel 1. Data Hasil Uji Anova Tes Pengetahuan Lingkungan

\begin{tabular}{lccc}
\hline \multicolumn{1}{c}{ Kelompok } & Jumlah Siswa & Rata-rata & Sig. \\
\hline Sekolah Adiwiyata Mandiri & 33 & 75,15 & 0,000 \\
\hline Sekolah Adiwiyata Nasional & 34 & 72,50 & \\
\hline Sekolah Non Adiwiyata & 28 & 71,25 & \\
\hline
\end{tabular}

Skor rata-rata sikap peduli lingkungan, yakni 72,24 pada sekolah adiwiyata mandiri dan adiwiyata nasional dan 58 pada sekolah non adiwiyata. Hal ini menunjukkan nilai sikap peduli lingkungan pada sekolah adiwiyata lebih tinggi dibandingkan nilai sikap peduli lingkungan pada sekolah non adiwiyata. Hasil uji hipotesis sikap peduli lingkungan pada sekolah adiwiyata dan non adiwiyata dapat dilihat pada tabel 2 .

Tabel 2. Data Hasil Uji Anova Angket Sikap Peduli Lingkungan

\begin{tabular}{lccc}
\hline Kelompok & Jumlah Siswa & Rata-rata & Sig. \\
\hline Sekolah Adiwiyata Mandiri & 33 & 72,24 & 0,000 \\
\hline Sekolah Adiwiyata Nasional & 34 & 72,24 & \\
\hline Sekolah Non Adiwiyata & 28 & 58 & \\
\hline
\end{tabular}

Ecological literacy siswa dalam aspek keterampilan mengatasi kerusakan lingkungan diporel skor rata-rata 74,67 pada sekolah adiwiyata mandiri, 72,24 pada sekolah adiwiyata nasional dan 70,86 pada sekolah non adiwiyata. Hasil uji hipotesis keterampilan dalam mencegah kerusakan lingkungan pada sekolah adiwiyata dan non adiwiyata dapat dilihat pada tabel 3. 
Tabel 3. Data Hasil Uji Anova Angket Keterampilan dalam Mencegah Kerusakan Lingkungan

\begin{tabular}{lccc}
\hline Kelompok & Jumlah Siswa & Rata-rata & Sig. \\
\hline Sekolah Adiwiyata Mandiri & 33 & 74,67 & 0,443 \\
\hline Sekolah Adiwiyata Nasional & 34 & 71,12 & \\
\hline Sekolah Non Adiwiyata & 28 & 70,86 & \\
\hline
\end{tabular}

Berdasarkan tabel 1, 2, dan 3 di atas, diketahui hasil uji anova satu jalur (one way anova) bahwa program adiwiyata berpengaruh terhadap ecological literacy siswa dari aspek pengetahuan lingkungan dan sikap peduli lingkungan dengan signifikan 0,000. Tabel 3 di atas, menunjukkan bahwa hasil uji anova satu jalur (one way anova) tidak terdapat perbedaan ecological literacy siswa dalam aspek keterampilan dalam mencegah kerusakan lingkungan pada sekolah adiwiyata dan non adiwiyata. Hasil uji homogenitas pengetahuan lingkungan diperoleh nilai $0,422>0,05$ hasil uji homogenitas sikap peduli lingkungan diperoleh nilai 0,916>0,05 dan hasil uji homogenitas keterampilan dalm mencegah kerusakan lingkungan diperoleh nilai $0,138>0,05$ artinya ketiga data tersebut memiliki data yang homogen.

\section{PEMBAHASAN}

Penelitian ini dilakukan pada sekolah adiwiyata mandiri, sekolah adiwiyata nasional dan sekolah non adiwiyata. Berdasarkan hasil penelitian telah diperoleh rata-rata nilai tes pengetahuan lingkungan, skor angket sikap peduli lingkungan dan skor angket keterampilan mengatasi kerusakan lingkungan. Rata-rata nilai tes pengetahuan lingkungan yakni, 75,15 pada sekolah adiwiyata mandiri, 72,50 pada sekolah adiwiyata nasional dan 61,25 pada sekolah non adiwiyata. Sekolah adiwiyata merupakan sekolah yang menginmplementasikan program adiwiyata yang dibentuk kementerian lingkungan hidup Indonesia dan bertujuan untuk menjadi sekolah berwawasan dan berbudaya lingkungan. Sekolah berbudaya lingkungan memiliki peran penting dalam memberikan perubahan lingkungan yang terjadi serta sebagai salah satu tempat dalam peningkatan pengetahuan dan kemampuan peserta didik (Muhajir \& Hidayatin, 2016).

Program Adiwiyata yang dikembangkan, meliputi kesetaraan, keadilan, kebersamaan, keterbukaan, dan kelestarian lingkungan hidup serta sumber daya alam atas dasar norma-norma dalam kehidupan (Landriany, 2014). Sekolah adiwiyata adalah sekolah yang kurikulumnya terintegrasi dengan pendidikan lingkungan. Pada beberapa negara melakukan upaya dalam mengintegrasikan pengetahuan lingkungan ke dalam kurikulum sekolah, yang dilakukan dengan cara yang berbeda pada tiap negara. Di Indonesia dilakukan dengan cara mengimplementasikan program adiwiyata pada setiap jenjang dan tingkatan sekolah. Namun, ada beberapa sekolah yang belum menerapkan program ini.

Pendidikan lingkungan merupakan proses menciptakan generasi atau populasi dunia dengan tujuan untuk meningkatkan kesadaran dan sikap peduli lingkungan, dan meningkatkan pengetahuan, motivasi, sikap, komitmen dan memiliki keterampilan dalam menjaga, melestarikan lingkungan, dan dapat memberikan solusi terhadap masalah lingkungan yang terjadi saat ini. Menurut (Utaya, Djatmika, Syafrudie, \& Degeng, 2018) pendidikan lingkungan merupakan subjek terpenting dalam pendidikan. (Kasi, Sumarmi, \& Astina, 2018) menyatakan bahwa dalam membangun kepedulian dan perhatian seseorang terhadap lingkungan yaitu dengan memberikan hal penting yaitu pengetahuan dan kesadaran mengenai ruang lingkup masalah lingkungan.

Pengetahuan lingkungan merupakan pengetahuan yang dimiliki oleh seseorang yang dapat membantu melestarikan dan melindungi lingkungan dari kerusakan lingkungan. Pendapat (Rini, Sukaatmadja, \& Giantari, 2017) pengetahuan lingkungan adalah seseorang yang memiliki pengetahuan ekologis mengenai konteks lingkungan. Pendapat (Igbokwe, 2016) seseorang yang menunjukkan bahwa dirinya memiliki literasi lingkungan yaitu seseorang yang bersedia untuk bertindak dengan tujuan untuk meningkatkan kesejahteraan orang lain, masyarakat dan dapat beradaptasi dengan kehidupan masyarakat lainnya, hal tersebut merupakan tindakan yang tepat dalam mengambil keputusan yang efektif serta cara yang baik dalam menerapkan pengetahuan lingkungan.

Hasil rata-rata skor angket sikap peduli lingkungan menunjukkan bahwa terdapat perbedaan ecological literacy siswa dalam aspek sikap peduli lingkungan pada sekolah adiwiyata dan non adiwiyata. Rata-rata skor angket sikap peduli lingkungan yakni, 72,24 pada sekolah adiwiyata dan 58 pada sekolah non adiwiyata. Peningkatan kepedulian siswa tidak hanya dilihat dari aspek pengetahuan saja, tetapi juga memadukan unsur sikap dalam proses pembelajaran (Karlina, Degeng, \& Amirudin, 2017). Informasi tentang isu lingkungan saat ini yaitu faktor yang memengaruhi tinggi atau rendahnya sikap peduli lingkungan yang dimiliki seseorang, faktor tersebut adalah jenis kelamin, usia, tempat tinggal (perkotaan atau pedesaan) agama, sosial ekonomi, politik pendidikan, kepribadian, pengalaman, dan pengetahuan lingkungan (Gifford \& Sussman, 2012).

Hasil penelitian sikap peduli lingkungan pada sekolah adiwiyata dan non adiwiyata menunjukkan bahwa program adiwiyata dapat membentuk sikap peduli lingkungan pada diri siswa. Program adiwiyata sangat penting diterapkan pada setiap jenjang dan tingkatan sekolah, untuk membentuk sikap peduli lingkungan siswa. Menurut (Saptono, 2011) sikap peduli lingkungan siswa dapat muncul pada saat siswa diajak untuk belajar sikap peduli dengan cara bertindak peduli. Selanjutnya, pendapat (Muhaimin, 2015) sikap yang berkenaan dengan moralitas lingkungan perlu dibentuk secara terus-menerus sehingga terbentuk kesadaran dan kepedulian terhadap lingkungan. 
Hasil uji hipotesis menunjukkan tidak terdapat perbedaan ecological literacy siswa dalam aspek keterampilan mencegah kerusakan lingkungan dengan taraf signifikansi yang diperoleh 0,443>0,05. Hasil skor rata-rata angket keterampilan mencegah kerusakan lingkungan, yakni 74,67 pada sekolah adiwiyata mandiri, 71,12 pada sekolah adiwiyata nasional dan 70,86 pada sekolah non adiwiyata. Hasil uji hipotesis menunjukkan tidak terdapat perbedaan ecological literacy siswa dalam aspek keterampilanmencegah kerusakan lingkungan. Namun, skor rata-rata tertinggi diperoleh sekolah adiwiyata mandiri, kemudian sekolah adiwiyata nasional dan skor rata-rata terendah diperoleh sekolah non adiwiyata. Hal ini menunjukkan program adiwiyata juga penting untuk meningkatkan ecological literacy siswa dalam aspek keterampilan mencegah kerusakan lingkungan. Menurut (Sumarmi \& Amirudin, 2014) salah satu cara untuk mengendalikan kerusakan lingkungan dapat dilakukan melalui kegiatan peduli terhadap lingkungan dan pembinaan etika lingkungan pada masyarakat.

Berdasarkan hasil penelitian di atas menunujukkan bahwa terdapat perbedaan ecological literacy siswa pada sekolah adiwiyata dan non adiwiyata dalam aspek pengetahuan lingkungan dan sikap peduli lingkungan. Tidak terdapat perbedaan ecological literacy siswa dalam aspek keterampilan mencegah kerusakan lingkungan. Hasil nilai rata-rata dari tes dan angket menunjukkan program adiwiyata dapat menumbuhkan ecological literacy siswa. Hal ini disebabkan karena sekolah adiwiyata dalam setiap mata pelajaran telah mengintegrasikan pendidikan lingkungan hidup dalam pembelajarannya. Menurut (Setyowati, 2014) Pendidikan formal di Indonesia adalah sekolah dan melalui program adiwiyata pada setiap jenjang dan tingkatkan sekolah pendidikan lingkungan hidup diintegrasikan ke dalam kurikulum sekolah

Hasil yang didapatkan dari uji anova untuk mengetahui ada tidaknya perbedaan ecological literacy siswa pada sekolah adiwiyata dan non adiwiyata menyatakan terdapat perbedaan pada dua aspek, yaitu pengetahuan lingkungan dan sikap peduli lingkungan, dan tidak terdapat perbedaan pada satu aspek yakni keterampilan mencegah kerusakan lingkungan. (Mcbeth \& Volk, 2010) mengungkapkan dalam mengaplikasikan perilaku ekologis lebih sulit dibandingkan dengan memiliki pengetahuan ekologis. Hal penting bagi individu untukdapat menampilkan perilaku ekologis tergantung interaksi hariannya.

\section{SIMPULAN}

Penelitian ini memperoleh kesimpulan, yakni (1) terdapat perbedaan pengetahuan lingkungan siswa pada sekolah adiwiyata dan non adiwiyata, (2) sikap peduli lingkungan siswa pada sekolah adiwiyata dan non adiwiyata, dan (3) tidak terdapat perbedaan keterampilan siswa dalam mencegah kerusakan lingkungan pada sekolah adiwiyata dan non adiwiyata. Saran yang dapat diberikan yakni, agar setiap sekolah menerapkan program adiwiyata dan sekolah yang telah menerapkan program adiwiyata agar memperhatikan keefektifan pelaksanaan program adiwiyata agar ecological literacy siswa dapat lebih meningkat.

\section{DAFTAR RUJUKAN}

Ardanita, B. A., Utaya, S., \& Ruja, I. N. (2017). Membentuk Karakter Peduli Lingkungan melalui Komunitas Pelajar Peduli Lingkungan Hidup (KPPLH). Prosiding TEP \& PDs: Transformasi Pendidikan Abad 21, 7(4), 969-974.

Gifford, R., \& Sussman, R. (2012). Environmental attitudes. Journal Psychology, Personality and Social Psychology, $10,3-18$. Igbokwe, B. A. (2016). Environmental Literacy Assessment: Assessing the Strength of an Environmental Education Program (EcoSchools) in Ontario Secondary Schools for Environmental Literacy Acquisition. In Electronic Theses and Disertasi. Kanada: University of Windsor.

Karlina, F., Degeng, I. N. S., \& Amirudin, A. (2017). Ecoliteracy Siswa SD Dalam Kegiatan Pengelolaan Sampah melalui Group Investigation Berbasis Outdoor Study. Jurnal Pendidikan: Teori, Penelitian, dan Pengembangan, 2(7), 991-1002.

Kasi, K., Sumarmi., \& Astina, I. K. (2018). Pengaruh Model Pembelajaran Service Learning terhadap Sikap Peduli Lingkungan. Jurnal Pendidikan: Teori, Penelitian, dan Pengembangan, 3(4), 437-440.

Kemendikbud. (2013). Dokumen Kurikulum 2013. Jakarta: Kemendikbud.

Keraf, A. S. (2014). Filsafat Lingkungan Hidup, Alam sebagai Sebuah Sistem Kehidupan Bersama Fritjof Capra. Yogyakarta: Kanisius.

Landriany, E. (2014). Implementasi Kebijakan Adiwiyata Dalam Upaya Mewujudkan Pendidikan Lingkungan Hidup di SMA Kota Malang. Jural Kebijakan dan Pengembangan Pendidikan, 2(1), 82-88.

Mahanal, S., \& Utaya, S. (2014). Pola Buku Ajar Pendidikan Lingkungan Hidup (PLH) sebagai Mata Pelajaran Muatan Lokal Sekolah Dasar untuk Mendukung Implementasi Pendekatan Saintifik. Proceeding Biology Education Conference Biology, Science, Environmental and Learning, 11(1), 1069-1074.

Mcbeth, W., \& Volk, T. L. (2010). The National Environmental Literacy Project : A Baseline Study of Middle Grade Students in the United States. The Journal of Environmentl Education, 41(1), 55-67. https://doi.org/10.1080/00958960903210031

Muhaimin. (2015). Membangun Kecerdasan Ekologis Model Pendidikan untuk Meningkatkan Kompetensi Ekologis. Bandung: Alfabeta.

Muhajir, \& Hidayatin, I. N. (2016). Sekolah Berbudaya Lingkungan Perspektif Pendidikan Islam: Implementasinya di SMAN 4 Pandeglang, Banten. AKADEMIKA, 21(1), 50-64. http://stainmetro.ac.id/e-journal/index.php/akademika/article/view/592 
Rini, A. S., Sukaatmadja, I. P. G., \& Giantari, I. G. A. K. G. (2017). Pengaruh Pengetahuan Lingkungan dan Kepedulian Lingkungan terhadap Sikap dan Niat Beli Produk Hijau “The Body Shop” Di Kota Denpasar. E-Jurnal Ekonomi dan Bisnis Universitas Udayana, 1(6), 137-166.

Rusmawan. (2017). Ecoliteracy dalam Konteks Pendidikan IPS. Jurnal Sosio Didaktika: Social Education, 4(2), 39-50.

Saptono. (2011). Dimensi-dimensi Pendidikan Karater. Jakarta: Erlangga.

Setyowati. (2014). Pendidikan Lingkungan Hidup: Buku Ajar MKU Lingkungan Hidup. Semarang: Universitas Negeri Semarang.

Sumarmi., \& Amirudin, A. (2014). Pengelolaan Lingkungan Berbasi Kearifan Lokal. Malang: Aditya Media Publishing.

The Center For Ecoliteracy. (2014). Ecoliteracy Competencies. http://www.ecoliteracy.org/discover/competencies

Utaya, S., Djatmika, E. T., Syafrudie, H. A., \& Degeng, I. N. S. (2018). Analiysis of Enviromental Education Content Materials at Adiwiyata Junior High Schools in East Java. CIEE Journal The University of Kitakyushu, (16). 